\title{
The Impact of Education Economy on Uzbekistan Based on Public Management
}

\author{
Rong Zhao \\ The University of World Economy and Diplomacy, Tashkent, Uzbekistan \\ Inner Mongolia Business \& Trade Vocational College, Hohhot, Inner Mongolia, China \\ DOI: $10.32629 /$ memf.v2i6.595
}

\begin{abstract}
In today's economic globalization, education plays an important role in public management. It can not only improve the overall quality of human society, but also a way of cultural communication. This paper mainly introduces the concept of public management and the characteristics of educational economy, and expounds the calculation method of educational economic contribution rate. Then, through investigation and research, this paper finds that there are many factors affecting educational equity. The most direct reason is that the government and schools lack reasonable planning for private schools, resulting in imperfect school facilities and high employment pressure on students; on the other hand, the rapid economic development leads to the shortage of talent supply, which leads to the decline of education quality. At the same time, based on the survey results, this paper finds that the penetration rate of primary and secondary education in Uzbekistan has increased significantly, the cultural level of adults and youth has improved, and gender equality in primary and secondary education opportunities.
\end{abstract}

Keywords: public management, educational economy, uzbekistan country, educational management

\section{Introduction}

In recent years, with the rapid development of economy, education is of great significance to public resource management. Educational equity is a hot issue of common concern all over the world. At present, Uzbekistan is relatively backward in development, slow economic growth, large gap between the rich and the poor and many other aspects have a certain degree of conflict with education ${ }^{[1-2]}$.

Many scholars have conducted relevant research on the educational economy of public management. Some researchers use some knowledge of information economics and international trade theory to study the contribution of economic growth to education. The conclusion seems to refute the human capital theory, but in fact, their goal is the same as the human capital theory ${ }^{[3-4]}$. Studies by other scientists have confirmed that human capital and education have a beneficial impact on economic growth, and estimated the contribution rate of education to economic growth. In addition, Russian educators have proposed a method similar to that of Dennison et al., but measure the contribution of education to economic growth ${ }^{[5-6]}$. The above research lays a foundation for the impact of education economy based on public management on Uzbekistan.

By analyzing the factors of education penetration in the provinces bordering Uzbekistan and other regions, this paper explores the reasons affecting its further development and narrowing the income gap, and puts forward corresponding countermeasures and suggestions to promote the coordinated and healthy economic and social development of the two countries.

\section{Discussion on the impact of education economy based on public management on Uzbekistan}

\subsection{Concept of public management}

Today, there are different opinions on what public administration is, and there is no consensus on many issues. The theoretical basis, research scope and direction of public management research are constantly changing and developing. The necessity for public management to become an independent practice and research field. The theoretical and practical value of public management as an independent discipline is increasingly recognized by people ${ }^{[7-8]}$. The public management discussed in this study involves the public management theory and practice that prevailed in the 1970s and flourished in the "new public management" movement; It is a new research method. In terms of word meaning, system is a scientific term, which generally refers to the combination of things within a certain range or similar according to a certain order and internal context ${ }^{[9-10]}$. Content system refers to the conceptual system and framework structure of expressing discipline theory. The "content 
system of educational economics and management" in this study refers to the knowledge or structural theory of educational economics and management, as well as the systematic concepts, principles and methods of educational economics and educational management. Each discipline represents a conceptual logic system. As an emerging discipline, the establishment of scientific content system is an important symbol of its development and maturity ${ }^{[11-12]}$.

\subsection{Overview of education economy under public management}

Public management education is the product of people's educational needs. As an existence, it is different from education. The purpose of education is to cultivate people in a general sense. To be exact, the theory of public management was formed at a certain historical stage of the development of social civilization. It is provided to the society alone or jointly by the state, groups or individuals. It is a public undertaking or serves all members of the society.

This concept can be understood from the following aspects:

First of all, public management training is a product of history, which will appear only after social civilization reaches a certain stage. In the second half of the 16th century, the promulgation of the compulsory education law marked the birth of public management education and made education a social resource. The emergence of public management education is objectively the need of the development of capitalist production. Subjectively, it is also the result of the struggle of the working class for democracy and the right to education.

Secondly, public management education is a relatively static public goods or quasi public goods. The purpose of public management training is to investigate the nature, characteristics, structure, function and role of educational resources in public management. Education public management is the basic management discipline of public management training.

Third, the theme and promoters of public management training are mainly reflected in the management of public management training. Public management training resources are the main body of public management training management. The policies, regulations and systems of public management training are the promoters of public management training management, and performance evaluation is the main management method of public management training. Public management education, also known as "public management education resources", includes public management education entrance resources and public management education export resources.

\subsection{Educational development in Uzbekistan}

Facing the growing demand for professionals, the Ukrainian government has made many major changes in the field of education under the leadership of current president mirziyoev. About 16 per cent of Uzbekistan's state budget is devoted to education for all. They divided the education system into three levels according to age: preschool education, primary and secondary education and adult education. The entire education system includes only primary schools, colleges, universities and vocational training institutions. Although the children are attending kindergartens, it was not until 2017 that the Ministry of preschool education of Uzbekistan established a new department in the national education system. The state stipulates that preschool classes are for children between the ages of 3 and 7. Children over the age of 7 must go to the first grade of primary school. The Ministry of national education of Uzbekistan is responsible for compulsory education and education. Compulsory education in public schools is completely free. Compulsory education includes primary and secondary schools for a total of 11 years. Primary school 4 years old, secondary school 7 years old. In the fifth year of study, students have the right to enter vocational secondary schools after graduation from grade 9. Vocational secondary schools have a two-year system. The Ministry of higher education and professional secondary education of Uzbekistan provides higher education (Bachelor's and master's) and vocational secondary education and training. There are 116 universities in China, including 21 foreign universities (Korean, Russian, Italian, Singapore and British universities, but no Chinese universities). The tuition fees of public colleges and universities vary according to their majors, about 12 million (about \$1200). Although there are many extracurricular education institutions, $90 \%$ of them rely on exam oriented education. For college entrance examination or studying abroad, students participate in training courses, mainly mathematics and English. Uzbekistan needs high-quality education and training facilities. Uzbekistan's long-term goal is to promote educational modernization and support national modernization. In the reform stage, Uzbekistan has particularly promoted the development of market-oriented private primary and secondary schools. Private schools and educational institutions in the service industry have high investment value and high education quality.

\subsection{Economic contribution rate of education}

\subsubsection{Representation method}

There are many ways to express the contribution rate of education to economic growth. To sum up, we can start with the estimation of index values in the following four aspects:

(1) The contribution of education to the new national income. 


$$
\text { Contribution ratio }=\frac{\Delta Y_{\mathrm{e}}}{\Delta Y}
$$

(2) The contribution of education to the growth rate of national income.

$$
\text { Contribution ratio }=\frac{\mathrm{y}_{\mathrm{e}}}{y}
$$

(3) The contribution of education to new labor productivity.

$$
\text { Contribution ratio }=\frac{\Delta\left(\frac{\mathrm{Y}}{\mathrm{L}}\right) e}{\Delta \frac{Y}{L}}
$$

(4) The contribution of education to the growth rate of labor productivity.

$$
\text { Contribution ratio }=\frac{\mathrm{S}_{\mathrm{e}}}{\mathrm{S}_{\mathrm{y}}}
$$

\subsubsection{Economic growth factor method}

Productivity refers to the combination of highly skilled labor and other factors of production to produce more products. Expressed by the marginal method, the production capacity is reflected as the amount of labor increased by each unit of education investment under the condition that other factors of production remain unchanged. The impact of education on the rate of economic growth is analyzed. The basic mode of this effect can be roughly summarized as follows:

$$
Y=\sum_{i=1}^{m} W_{\mathrm{i}} d_{i}+\sum_{i=1}^{n} b_{i}+a
$$

Where $\mathrm{y}$ is the growth rate of national income (calculated at constant prices); Di is the growth rate of the ith factor affecting economic growth; Wi is the weight of the second factor; $\mathrm{Bi}$ is the growth rate of the input-output factor of the ith unit; $\mathrm{A}$ is the growth rate of knowledge progress and others.

\section{Experiment}

\subsection{Investigation purpose}

This paper investigates the current situation of the impact of education economy in Uzbekistan, mainly the impact of education economy in Uzbekistan at the present stage and relevant suggestions, so as to provide a basis for the research on the impact of education economy on Uzbekistan based on public management.

\subsection{Investigation process}

\subsubsection{Determination of respondents}

This paper studies the impact of education economy based on public management on Uzbekistan, so the research object is education in Uzbekistan. In order to ensure the accuracy of the survey object and consider the problems of long distance and inconvenient travel in Uzbekistan, this paper selects the way of online questionnaire survey. Therefore, the education penetration rate of all levels in Uzbekistan was selected as the survey object.

\subsubsection{Determination of the number of questionnaires}

The determination of the number of questionnaires is an important factor affecting the survey results. Therefore, according to the minimum sample size of the number of questionnaires and the actual situation of this survey activity, this paper determines that the number of questionnaires is 600. In view of the simple recovery degree of online questionnaire survey, more questionnaires are recovered in this survey, 560 questionnaires are recovered, and some invalid questionnaires are eliminated. Finally, 520 valid questionnaires were obtained. 


\section{Discussion}

\subsection{Analysis of education popularization in Uzbekistan}

The education penetration rate of Uzbekistan in the past, and the education penetration rate of Uzbekistan now. As can be seen from the comparison between the difference, the penetration rate of primary and secondary education has increased significantly, the educational level of adults and youth has improved, and gender equality in primary and secondary education opportunities.

\subsection{Problems in education in Uzbekistan at the present stage}

First, there is a lack of unified and coordinated educational fiscal policy, and the relationship between Uzbekistan's school education system and social education system and educational training activities has not been solved. Second, Uzbekistan has insufficient investment in education. At present, Uzbekistan's investment in education, both relative and absolute, lags far behind Uzbekistan's industrialized countries and many developing countries. The problems of dropping out of school, leaving early and left behind children still exist. Many students drop out of school mainly because of their poor academic performance. The concept of some parents is still farmers' awareness. They only pay attention to immediate interests and ignore long-term planning. They let their children contact the society in advance and make a living by working. A few people drop out of school to work because of family financial difficulties. It is assumed that the proportion of boys dropping out of school is higher than that of girls, and boys are more tired of school than girls. Therefore, to fully understand the importance of education investment to Uzbekistan's economic growth and strive to change the current situation of investment, education investment has extremely important strategic significance in Uzbekistan. On the whole, the overall quality of teachers can not fully meet the needs of educational reform and development in the new era, and the development of teacher training is unbalanced, especially in rural areas with few training opportunities. The normal education system needs to be improved and the supporting capacity needs to be strengthened. Third, the raising channel of education funds is single. Governments at all levels do not have sufficient restrictions on education investment, and schools must be allowed to raise funds through various channels. However, when schools are allowed to raise funds through various channels without a comprehensive and standardized funding mechanism, arbitrary charges are inevitable. The problem of arbitrary charges for education lies in schools, but the "offside" of tuition fees is largely caused by the "lack of responsibility" of government investment in education.

\section{Conclusion}

In recent years, the trend of economic globalization has been strengthened. As the basic construction of Uzbekistan, education is of great significance to the improvement of the overall quality and ability of the people. In this situation, the government has issued a series of policies to promote the development of Ukrainian public administration. By using econometric methods, this paper analyzes some existing problems in Uzbekistan and puts forward corresponding countermeasures and suggestions. It is hoped that it can provide reference for improving the conditions for private schools, enable more citizens to enjoy educational benefits and bring greater economic benefits, and also contribute to social progress and development.

\section{References}

[1] Xu X, Liu C. Research on the Impact of Expressway on the County Economy Based on a Spatial DID Model: The Case of Three Provinces of China[J]. Mathematical Problems in Engineering, 2021, (2): 1-13.

[2] Hudaykulov A, Xu H, Galib M A. Impact of Goal Orientation Theory on Social Capital: The Implications for Effective Team Cooperation in Uzbekistan Textile Industry[J]. Online Submission, 2017, 5(7): 16688-16709.

[3] Li miaoran, Zhai Mingyue, Cao Yujie. Research on the impact of innovation and entrepreneurship education reform on College Students' employment and entrepreneurship[J]. Chinese college students' employment (theoretical Edition), 2019, 000(007): 55-59.

[4] Zhang X. Research on the Impact of Foreign Direct Investment on Chinese Trade Structure Optimization — Based on the Strategic Background of the Belt and Road[J]. Modern Economy, 2019, 10(3): 797-810.

[5] Hayden L B. Prof. Sebastiano B. Serpico: Modeling the Important Impact of Research on Education [Education][J]. IEEE Geoscience and Remote Sensing Magazine, 2020, 8(3): 100-101.

[6] Vorontsova A, Shvindina H, Mayboroda T, et al. The impact of state regulation in a sphere of education on sustainable development of national economy[J]. Problems and Perspectives in Management, 2020, 18(4): 275-288. 
[7] Lee Y. Examining the Impact of STEAM Education Reform on Teachers' Perceptions about STEAM in Uzbekistan[J]. Asia-Pacific Science Education, 2021: 1-30.

[8] Demral Z. The Effect of Vocational Training/Education Activities on Employee Leaving Tendency in Organisations: A Survey-Based Research on Practices in Turkey[J]. Gaziantep University Journal of Social Sciences, 2017, 16(4): 10141029.

[9] Zhou Ying. Research on the ideological and political education of college students based on "human care" and "psychic counseling"[J]. Science, education and culture, 2017, 000(019): 7-8.

[10] Cai Chong, Zhu Cheng, Huang Lihong. Research on the connotative development of practical teaching based on innovation and entrepreneurship educator - an example in biotechnology major of industrial characteristic university[J]. College biology teaching and Research (electronic version), 2018, 008(003): 39-43.

[11] Salakhova E, Shamsitdinova M, Shakhakimova M. THE IMPACT OF INFORMATION TECHNOLOGIES ON DISTANCE EDUCATION DURING PANDEMIC IN THE REPUBLIC OF UZBEKISTAN[J]. PalArch's Journal of Archaeology of Egypt/ Egyptology, 2020, 17(6): 8962-8967.

[12] Chai Yangli, Chen Xiangdong, Li Yu. Research on the Social Interaction in Online Reading and its Impact: Based on the Investigation of "WeRead"[J]. Open education research, 2018, 024(004): 90-100. 